\title{
A further theoretical report on the main behavioral animal models of depression and their metabolic relevance (II)
}

\author{
Andrei Ciobîcă, Alexandra Săvucă, Alin Ciobîcă, \\ Daniel Timofte, Walther Bild
}

\begin{abstract}
Andrei Ciobîcă - PhD student, “Grigore T.Popa” University of Medicine and Pharmacy, Iaşi, Romania

Alexandra Săvucă - Faculty of Biology, Alexandru Ioan Cuza University, Iaşi, Romania Alin Ciobîcă - Department of Research, Faculty of Biology, Alexandru Ioan Cuza University, Iaşi, Romania, Academy of Romanian Scientists, Bucureşti, Romania, Center of Biomedical Research, Romanian Academy, Iaşi

Daniel Timofte - MD, PhD, professor, “Grigore T.Popa” University of Medicine and Pharmacy, Iaşi, Romania

Walther Bild - MD, PhD, professor, Department of Physiology, "Grigore T.Popa" University of Medicine and Pharmacy, Iaşi, Romania
\end{abstract}

\begin{abstract}
While we previously described helplessness learned model and chronic mild stress (CMS) model, in the present mini-review we continue our interest in describing the main animal models of depression (e.g. we present here the forced swim test and tail suspension test), their neuropsychiatric relevance, as well as the way there are correlated with some related metabolic manifestations.
\end{abstract}

\section{KEYWORDS:}

Depression, models, neuropsychiatric, metabolic.

\section{INTRODUCTION}

Depression is a heterogeneous disorder, with many phases, with symptoms manifested on a psychological level, behavioral and physiological. This is why it is so difficult to imitate this disorder in the laboratory (1). Many of the human symptoms of depression, as described in Diagnostic and Statistical Manual of the American Psychiatric Association (DSM IV) (such as recurrent thoughts of death or suicide or who have excessive thoughts of guilt), are impossible to involve in a depression mice model. The question, therefore, remains valid as to whether we can ever assume that a mouse is "depressed". Evolutionary theories have been proposed for psychiatric disorders $(2,3)$ which would plausibly imply that animal species smaller ones may exhibit useful behaviors in modeling human depression. 


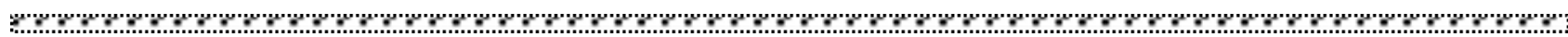

However, such hypotheses are strongly debated and are difficult to approach empirically (4, 5). Another difficulty in evaluating rodent depressive states is that the pathophysiology underlying depression is still unresolved. Moreover, the mode of action of clinically effective antidepressants is not yet understood beyond the fact that they mainly alter neurotransmission of monoamines $(6,7$, 8).

Despite the difficulties of translating the complexity of human affective disorders across the whole spectrum into relevant tests in mice, numerous attempts have been made to create so-called animal models of depression or at least models of some essential aspects of depression. Some models include those paradigms in which different states, pharmacological manipulations, lesions, environmental or genetic are applied $(9,10)$.

In this way, in the present mini-report we are mainly further describing additional (11) animal models of depression for rodents in two types of tests (e.g. the forced swim test and tail suspension test), as well as briefly reporting some of their metabolic relevance.

\section{FORCED SWIM TEST}

In the forced swim test, also known as the Porsolt test (12), a mouse or rat is placed in a water cylinder from which it cannot escape and, after an initial period of struggle, swimming and climbing, the animal presents in the followed a floating posture and motionless. The immobility in the model of forced swimming has been interpreted as an expression of behavioral desperation or entrapment $(13,14)$ and is reversed by the acute administration of almost all available antidepressants. This is a problem for the model because the current antidepressants establish mood in depressed people only after several weeks of administration. Numerous agents that act independently of monoamine signaling, such as recombinant ghrelin (15), ketamine (16) and estradiol (17), have also been shown to reduce this immobilization time. The most important thing of these models is their ability to rapidly examine new agents and the phenotype of genetically manipulated mice, and both paradigms have been successfully automated to reduce errors in subjective evaluation. There seems to be a much larger number of knockouts (KO) like how antidepressant works, in those mice that have reduced immobility, compared to the number of KOs that have increased immobility, but this may reflect a pattern constraint. Because it was initially designed to capture antidepressant effects. These studies illustrate the number and diversity of genes that may play a role in regulating stressinduced immobility, including transcription factors, growth factors, endocrine hormones, immune signaling molecules, and the many genes that encode proteins required for synaptic neurotransmission.

During this test, an animal is placed in a container filled with water from which it cannot escape. The animal will first try to escape, but in the end it will present immobility (i.e. it floats with the absence of any movement, except those necessary to keep the nose above the water). This is a very popular model in animal research for several reasons. First, it involves exposing animals to stress, which has been shown to play a role in the tendency of major depression $(18,19)$. Moreover, depression is often viewed as a lack of ability to cope with stress $(20,21,22)$. Second, pharmacological treatment with antidepressants prior to testing has been shown to reduce immobility in the forced swim test $(23,24,25,26,27,28)$. Therefore, it is often used as a screening test for novel compounds with potential antidepressant properties (29). In addition, the forced swim test has been shown to share some of the factors that are influenced or altered by depression in humans, such as changes in dietary intake, sleep abnormalities, and withdrawal induced anhedonia (30). This is also the reason why this test is sometimes used to evaluate depressive behavior in mutant mice, with increasing or decreasing basal immobility (compared to "wild" mice) $(31,32)$. 
The forced swim test is used to monitor depressive behavior and is based on the hypothesis that immobility reflects a measure of behavioral despair (33). The main advantages of this procedure are relatively easy operation and fast results. Moreover, its sensitivity to a wide range of antidepressant drugs that makes it an appropriate screening test is one of the most important characteristics that lead to its high predictive validity. It is important to differentiate between these drugs that are not intended for the treatment of depression such as benzodiazepines, which have been shown to have anti-anxiety effects (33). Another example of the value of the forced swim test in the study of depression, which also contributes to the validity of the facade, is that models of depression predisposition have been found that influence the behavior of immobility. For example, its use as a marker of depressive behavior in genetic research. Genetic models of depression in animals have successfully reproduced rodents based on their immobility in the forced swimming test (34), suggesting that immobility is determined by a hereditary trait, although some strains have shown high immobility in this test $(35$, 36) .In addition, it is important to mention that genetic models that do not rely on performance in the forced swim test have proven to be successful in providing valid models for studying depressive behavior (37, 38).In addition to genetic research, it has been shown that immobility behavior during forced swim testing is influenced by several animal models that are related to depression predisposition, such as early exposure to stress $(39,40)$, diabetes $(41,42)$ and drug addiction (43).

Despite his appeal, reservations were also raised regarding the construct validity, which cast doubt on the fact that this is a model for depression. For example, extrapolation is problematic in this test because, in real life, patients should be treated for at least a few weeks before they feel any improvement in their symptoms $(44,45,46)$. This raises the question whether immobility in forced swim testing and depression share the same longterm adaptive changes in the neural circuits that underlie the effects of antidepressants in humans. However, it is important to note that several recent studies have shown antidepressant effects in this test after chronic treatment at doses much lower than those needed to induce effects after acute administration (47). Another widely discussed issue is the precise meaning of immobility behavior as a measure that reflects the symptoms of depression (48). It is important to note that immobility in these tests appears to be the result of an inability or reluctance to maintain effort, rather than generalized hypoactivity. This is of particular importance because patients with depression present with psychomotor disorders, especially in those tests that measure the duration of effort (49). Active behaviors in this model (e.g., fighting and swimming) may lead to escape and, as a result, decrease stress, while passive behavior (i.e. immobility) may retain energy while waiting for a possible escape. The choice of animal behavior varies and depends on many factors (e.g. pre-exposure, energy status, treatment, etc.). SSRI's (selective serotonin reuptake inhibitors) have shown to delay the transition from active to passive coping strategies, while factors associated with depression accelerate this transition (49). Moreover, some questions were raised about immobility as a learned process, which could mean that the animal might find out that the best solution is to adopt a passive behavior and wait for it to be taken out of the water by the experimenter, what has been described as immobility learned in specialized literature $(50,51,52)$. However, it could be argued that this vision leads to an anthropomorphic perspective of this model. In addition, the negative correlation between longer duration of immobility and stress hormones was not found $(53,54)$. Furthermore, it was found that SSRI inhibitors reduce immobility in a single test session after chronic administration in rats or even after acute administration in mice, suggesting that if SSRIs are involved, learned immobility might not play a role (55).

Another important notion is the role of active behaviors during forced swim test. Although immobility is the behavior presented in the articles, the other two measures were also 


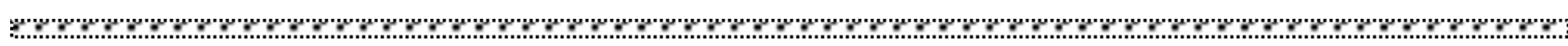

significant. Specifically, antidepressants that increase serotoninergic neurotransmission have led to longer swimming durations, while antidepressants that have been shown to increase catacholaminergic neurotransmission have led to long bouts (55). This may help us to differentiate the neurochemical mechanisms underlying this behavior in different experiments $(56,57,58,59)$.

In addition, due to the fact that some antidepressants are known to reduce locomotor activity and also that drugs such as psychomotor stimuli have been shown to reduce immobility in the forced swim test but are not effective in treating depression, it is recommended pre-test that measures the locomotor activity in addition to the forced swim test to exclude the fact that the level of activity base is not the determining factor in this model (60). Moreover, due to the averseness of this test, it is important to take into account the possible influences that could have on the structure/function of the brain if brain analysis is to be performed following this procedure. Also, when preforming a number of behavioral tests, if the other paradigms are not considered stressful, it is recommended that the forced swim test be the last test performed, in order not to influence any future tests.

Lastly, although, in the past, scoring in this procedure was subject to bias by the experimenter, today it is recommended to use the designated software that practically eliminates this disadvantage $(61,62)$.

In addition, our research group previously reported on this test (63), clearly demonstrating for example some neuropsychiatric improvements of a specific methanolic extract of Hibiscus asper leaves, as well as its metabolic relevance, especially considering the latest increased awareness on the plant extracts relevance in both neuropsychiatric and metabolic disorders (64, $65)$.

Thus, according to Thakur et al. group (64) the correlation between these two aspects could be mechanistically explained and approached by mainly focusing on the glucose metabolism and its connections to neuroenergetics, neurotransmission, energy storage, biosynthesis and oxidative stress status modifications (64).

\section{TAIL SUSPENSION TEST}

Even since its introduction as a new model for detecting antidepressant activity in 1985, the use of the tail suspension test has shown that depression symptoms can be replicated in mice. The amount of data generated over the next two decades, especially over the last years, has shown that the inevitable stress of hanging a tail mouse can provide invaluable information about people's ability to cope with a stressful situation. Moreover, and probably most important for the development of antidepressant drug, studies with the tail suspension test have shown that this coping behavior can be subsequently modified by pharmacological or genetic manipulations relevant to depression and the effect of antidepressants. This section will focus on the usefulness of the tail suspension test to evaluate the effects of pharmacological and genetic manipulations relevant to depression and antidepressant response.

Possible disadvantages of the tail suspension test. As with all rodent models, there are disadvantages to the tail suspension test.

(i) Although one of the major benefits of the tail suspension test is that this test is generally a relatively rapid one that measures the immediate action of antidepressants and is sensitive to short-term antidepressant effects, it can also be perceived as one of the major weaknesses associated with it. With its use, because it is in contrast to the observation that chronic antidepressant treatments in humans usually last for a longer period of time. That said, there is evidence that some behavioral changes occur early in antidepressant treatment in humans, which may predict or at least be relevant to the later therapeutic outcome $(65,66)$. It can therefore be speculated that immobility present in the tail suspension test may be sensitive to some of these early effects of antidepressants. 
(ii) Another disadvantage arises from the fact that some commonly used mouse strains, such as $\mathrm{C} 57 \mathrm{Bl} / 6$, would not be the ideal strain to use in the tail suspension assay because many animals with this genetic background have a tendency to climb on its own tail (67). Accordingly, some authors suggest the need for much larger batches of animals if the tail suspension test is to be included in a behavioral testing battery using $\mathrm{C} 57 \mathrm{Bl} / 6$ mice. From the analysis, because they learned that escape is possible and will quickly resume such a stature (even 24 hours later). Obviously, caution should be exercised by those experimenters who use automatic devices that do not allow the observation per se of mice, as potential climb can influence behavioral reading. Furthermore, it would be useful for the experimenters to delineate what percentage of animals climbed the tail in their studies to determine the extent of tail scaling in mice from different suppliers and different behavioral models. Interestingly, Yoshikawa and colleagues (68) argued that this potential problem can be successfully overcome by introducing a methodological change; Instead of attaching the tail of the mouse to a fixed support, it attaches the tail to a hook that is connected to a perpendicular wire and a voltage indicator that prevents the animal from climbing.

As with the forced swim test, the tail suspension test is based on the observation that rodents (almost always mice, although gerbils and rats were used) $(69,70)$ after initial evacuation movements, develop a state of immobility when placed in an unavoidable stressful situation. In the case of the tail suspension test, the stressful situation involves the hemodynamic stress of being hanged uncontrollably by the tail, while, as we mentioned in the previous chapter, the mice in the forced swim test are placed in a cylinder filled with water (71). If antidepressant treatments are given before testing, subjects will actively persist in engaging in escape-oriented behaviors for longer periods of time compared to the animals in the control group. The test is usually quite short, 6 minutes and the time spent in the building is recorded either manually or through an automatic device (72). Acute antidepressant treatments lower these immobility scores. An obvious advantage of this test is its ability to detect a wide spectrum of antidepressants, regardless of their basic mechanism, is relatively inexpensive, methodologically unsophisticated and easily accessible for automation. Also, the automation allows the evaluation of additional parameters such as the power of movement $(73,74)$ and, more recently, the energy of the movement. The advent of genetically modified mice has put additional emphasis on the use and development of animal depression models. Thus, the use has increased substantially in recent years as a model for the evaluation of antidepressant behavior. Although both the forced swim test and the tail suspension test are similar in the constructs they intend to evaluate, they are probably different in terms of the biological substrates underlying the observed behavior, although they often provide convergent data on antidepressant potential $(75,76,77)$. Among the most important differences between the forced swim test and the tail suspension test are:

- The tail suspension test avoids any possible confusion caused by hypothermic exposure which may be problematic in the forced swim test, especially if a target gene is involved in the thermoregulation processes. Indeed, the tail suspension test, like many other acute stressors, induces a hyper-thermal response in animals (78).

- The tail suspension test also eliminates the need to swim the mouse that may be relevant in studying genetically modified animals with compromised motor coordination. For example, mice in strain 129, which had problems maintaining surface water during forced swim testing after antidepressant treatment (79), did not encounter any difficulty when participating in the tail suspension test. However, the tail suspension test is also dependent on a motor component and animals with severe motor phenotypes can also provide misleading information. 
s.

- Another difference is that, in the case of the animals tested in the model of forced swimming, the animals engage in rapid periods of active behavior, and immobility usually occurs only in the third minute of the test. In the tail suspension test, animals can become immobile much faster, but remain immobile for a significantly shorter period of time than in the case of forced swimming, so immobility scores are calculated over the entire duration of the test.

- Initial immobility may also vary substantially between the two tests. For example, by comparing the initial immobility between the forced swim test and the tail suspension test, Bai and colleagues (76) demonstrated that mice on a NIH-Swiss strain exhibit a seven-fold lower immobility in the tail suspension test than in the test. Forced swim test. Interestingly, the baseline immobility between the two tests using C57B1/6 mice was comparable.

- Perhaps one of the most important differences is the response to drugs in both tests and the increased sensitivity of the tail suspension test. The mouse forced swim test was not commonly regarded as a consistently sensitive model for detecting the activity of selective serotonin reuptake inhibitors (80) while these antidepressants are generally reported as active in the tail suspension assay. More recently, it is becoming clear that procedural changes and better strain selection may increase sensitivity to the detection of selective serotonin reuptake inhibitors in the forced swim test (81). In contrast, other atypical agents, such as rolipram and levoprotillin, reduce immobility in the forced swim test, but have been reported inactive in the tail suspension test (80). It has recently been shown that, while the GABA receptor antagonist or genetic destruction results in an antidepressant effect in the forced swim test, no effect was observed in the tail suspension model (82). Another difference between tests is their differential sensitivity to the effects of reducing the immobility of different antidepressants. Furthermore, the doseresponse model may be substantially different between the two procedures. It is not unusual for these compounds to have a two-phase response to behaviorally relevant doses in the forced swim test $(83,84,85,86)$, and the model is relatively unusual in the tail suspension test. An example of this is the recent demonstration that antidepressant imipramine had a U-dose response in the forced swim test, while a linear pattern of activity was observed in the tail suspension test at the same dose range (86).

In addition, on the metabolic level, the depressive symptoms are more and more associated with classical metabolic disorders such as diabetes (87), but also related disorders such as the metabolic syndrome (88) and of course obesity and overweight on their own (89).

Also, all these aspects could open the discussion on the brain gut-relations as our group previously demonstrated $(90,91,92)$ and the relevance of the intestinal microbiota on various neuropsychiatric disorders, which our research group also showed before (93, 94, 95).

\section{CONCLUSION}

All the data regarding these animal models we presented in these two mini-reviews could open new perspectives of research in this area, as well better understanding the mechanists behind these processes and the way there are modeled.

\section{ACKNOWLEDGEMENTS AND DISCLOSURES}

The authors are stating that there is no conflict of interest to disclose, except for Ciobîcă Alin which is supported by a Young Teams grant offered by UEFISCDI Romania, no. PN-III-P1-1.1-TE-20161210, contract no. 58 from 02/05/2018. 


\section{REFERENCES}

1. American Psychiatric Association, 1994. Anon., 1994. Diagnostic and statistical manual of mental disorders, fourth ed. American Psychiatric Press, Washington, DC.

2. Nesse RM. Is depression an adaptation?. Arch Gen Psychiatry 2000; 57:14-20.

3. Dubrovsky B. Evolutionary psychiatry. Adaptationist and nonadaptationist conceptualizations. Prog Neuropsychopharmacol Biol Psychiatry 2002; 26: 1-19.

4. McLoughlin G. Is depression normal in human beings? A critique of the evolutionary perspective. Int J Ment Health Nurs 2002; 11: 170-173.

5. Nestler EJ, Barrot M, DiLeone RJ, Eisch AJ, Gold SJ, Monteggia LM. Neurobiology of depression. Neuron 2002; 34: 13-25.

6. Frazer A. Antidepressants. J Clin Psychiatry 1997;58 (suppl 6), 9-25.

7. Blier P. Possible neurobiological mechanisms underlying faster onset of antidepressant action. J Clin Psychiatry 2001;62 (suppl 4), 7-11. (Discussion 37-40).

8. Cryan JF, Markou A, Lucki I. Assessing antidepressant activity in rodents: recent developments and future needs. Trends Pharmacol Sci 2002a;23, 238-245.

9. Cryan JF, O’leary OF, Jin S, Friedland JC, Ouyang M, Hirsch BR, et al. Norepinephrine deficient mice lack responses to antidepressant drugs, including SSRIs. PNAS 2004;101, 8186-8191.

10. Berton O, Nestler EJ. New approaches to antidepressant drug discovery: beyond monoamines. Nat Rev Neurosci 2006; 7: 137-151.

11. A. Ciobica, A. Savuca, A. Ciobica, D. Timofte, W. Bild. A mini-review through the main behavioral animal models of depression and their metabolic relevance, Bulletin of Integrative Psychiatry 2019;2:81, 63-73.

12. Porsolt RD, Le Pichon M, Jalfre M. Depression: a new animal model sensitive to antidepressant treatments. Nature. 1977; 266:730-732.

13. Cryan JF, Mombereau C, Vassout A. The tail suspension test as a model for assessing antidepressant activity: review of pharmacological and genetic studies in mice. Neurosci Biobehav Rev. 2005; 29:571-625.

14. Lucki I, Dalvi A, Mayorga AJ. Sensitivity to the effects of pharmacologically selective antidepressants in different strains of mice. Psychopharmacology (Berl). 2001; 155:315-322.

15. Lutter M, Sakata I, Osborne-Lawrence S, Rovinsky SA, Anderson JG, Jung S, Birnbaum S, Yanagisawa M, Elmquist. JK, Nestler EJ, Zigman JM. The orexigenic hormone ghrelin defends against depressive symptoms of chronic stress. Nat Neurosci. 2008; 11:752-753.

16. Maeng S, Zarate CA Jr, Du J, Schloesser RJ, McCammon J, Chen G, Manji HK. Cellular mechanisms underlying the antidepressant effects of ketamine: role of alpha-amino-3-hydroxy-5- methylisoxazole-4-propionic acid receptors. Biol Psychiatry. 2008; 63:349-352.

17. Dhir A, Kulkarni SK. Antidepressant-like effect of 17beta-estradiol: involvement of dopaminergic, serotonergic, and (or) sigma-1 receptor systems. Can J Physiol Pharmacol. 2008; 86:726-735.

18. Doron R, et al. A novel herbal treatment reduces depressive-like behaviors and increases BDNF levels in the brain of stressed mice. Life sciences. 2014;94:151-157.

19. Caspi A, et al. Influence of life stress on depression: Moderation by a polymorphism in the 5-HTT gene. Science. 2003;301:386-389.

20. Kaufman J, et al. Brain-derived neurotrophic factor-5-HTTLPR gene interactions and environmental modifiers of depression in children. Biological psychiatry. 2006;59:673-680.

21. Anisman H, Zacharko RM. Multiple neurochemical and behavioral consequences of stressors: Implications for depression. Pharmacology and Therapeutics. 1990;46:119-136.

22. Kessler RC. The effects of stressful life events on depression. Annual Review of Psychology. 1997;48:191214.

23. Sullivan PF, Neale MC, Kendler KS. Genetic epidemiology of major depression: Review and meta-analysis. American Journal of Psychiatry. 2000;157:1552-1562.

24. Cryan JF, Valentino RJ, Lucki I. Assessing substrates underlying the behavioral effects of antidepressants using the modified rat forced swimming test. Neuroscience and biobehavioral reviews. 2005;29:547-569.

25. Detke MJ, Lucki I. Detection of serotonergic and noradrenergic antidepressants in the rat forced swimming test: The effects of water depth. Behavioural Brain Research. 1996;73:43-46.

26. Hemby SE, et al. Potential antidepressant effects of novel tropane compounds, selective for serotonin or dopamine transporters. Journal of Pharmacology and Experimental Therapeutics. 1997;282:727-733. 


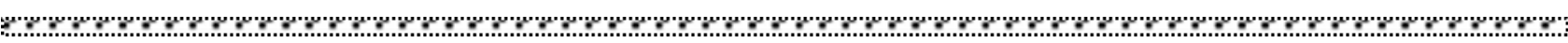

27. Bouvard M, Stinus L. In the rat forced swimming test, chronic but not subacute administration of dual 5HT/NA antidepressant treatments may produce greater effects than selective drugs. Behavioural Brain Research. 2002;136:521-532.

28. Page ME, Detke MJ, Dalvi A, Kirby LG, Lucki I. Serotonergic mediation of the effects of fluoxetine, but not desipramine, in the rat forced swimming test. Psychopharmacology. 1999;147:162-167.

29. Rubalcava C, Lucki I. Strain differences in the behavioral effects of antidepressant drugs in the rat forced swimming test. Neuropsychopharmacology. 2000;22:191-199.

30. Cryan JF, Mombereau C, Vassout A. The tail suspension test as a model for assessing antidepressant activity: Review of pharmacological and genetic studies in mice. Neuroscience and biobehavioral reviews. 2005;29:571625.

31. Cryan JF, Mombereau C. In search of a depressed mouse: Utility of models for studying depression-related behavior in genetically modified mice. Molecular Psychiatry. 2004; 9:326-357.

32. Sang KP, et al. Par-4 links dopamine signaling and depression. Cell. 2005;122:275-287.

33. Borsini, F., Meli, A. Is the forced swimming test a suitable model for revealing antidepressant activity. Psychopharmacology. 94, 147-160 (1988).

34. Reinhold JA, Mandos LA, Rickels K, Lohoff FW. Pharmacological treatment of generalized anxiety disorder. Expert opinion on pharmacotherapy. 2011;12, 2457-2467.

35. Estrada-Camarena E, Fernandez-Guasti,A, Lopez-Rubalcava C. Interaction between estrogens and antidepressants in the forced swimming test in rats. Psychopharmacology. 2004;173, 139-145.

36. Weiss JM, Kilts CD. Animal models of depression and schizophrenia. Textbook of Psychopharmacology. 1998;89-131.

37. Armario A, Gavaldà A, Martí J. Comparison of the behavioural and endocrine response to forced swimming stress in five inbred strains of rats. Psychoneuroendocrinology 1995; 20, 879-890.

38. Paré WP. Open field, learned helplessness, conditioned defensive burying, and forced-swim tests in WKY rats. Physiology and Behavior. 1994;55, 433-439.

39. Overstreet DH, Friedman E, Mathe AA, Yadid G. The Flinders Sensitive Line rat: a selectively bred putative animal model of depression. Neuroscience and biobehavioral reviews. 2005;29, 739-759.

40. Piras G, Piludu MA, Giorgi O, Corda MG. Effects of chronic antidepressant treatments in a putative genetic model of vulnerability (Roman low-avoidance rats) and resistance (Roman high-avoidance rats) to stress-induced depression. Psychopharmacology. 2014;231, 43-53.

41. Bielajew C, et al. Strain and Gender Specific Effects in the Forced Swim Test. Effects of Previous Stress Exposure. Stress. 2003;6, 269-280.

42. Fujisaki C, et al. An immnosuppressive drug, cyclosporine-A acts like anti-depressant for rats under unpredictable chronic stress. Journal of Medical and Dental Sciences. 2003;50, 93-100.

43. Gomez R, Vargas CR, Wajner M, Barros HMT. Lower in vivo brain extracellular GABA concentration in diabetic rats during forced swimming. Brain research. 2003;968, 281-284.

44. Hilakivi-Clarke LA, Wozniak KM, Durcan MJ, Linnoila M. Behavior of streptozotocin-diabetic mice in tests of exploration, locomotion, anxiety, depression and aggression. Physiology and Behavior. 1990;48, 429-433.

45. Cryan JF, Hoyer D, Markou A. Withdrawal from chronic amphetamine induces depressive-like behavioral effects in rodents. Biological psychiatry. 2003;54, 49-58.

46. Portella MJ, et al. Can we really accelerate and enhance the selective serotonin reuptake inhibitor antidepressant effect? A randomized clinical trial and a meta-analysis of pindolol in nonresistant depression. The Journal of clinical psychiatry. 2011;72, 962-969.

47. Machado-Vieira R, Salvadore G, Luckenbaugh DA, Manji HK, Zarate CA. Rapid onset of antidepressant action: a new paradigm in the research and treatment of major depressive disorder. The Journal of clinical psychiatry. 2008;69, 946-958.

48. Bordet R, Thomas P, Dupuis B. Effect of pindolol on onset of action of paroxetine in the treatment of major depression: intermediate analysis of a double-blind, placebo-controlled trial. Reseau de Recherche et d'Experimentation Psychopharmacologique. The American journal of psychiatry. 1998;155, 1346-1351.

49. Dulawa SC, Holick KA, Gundersen B, Hen R. Effects of chronic fluoxetine in animal models of anxiety and depression. Neuropsychopharmacology. 2004;29, 1321-1330.

50. Willner P. Animal models of depression: An overview. Pharmacology and Therapeutics. 1990;45, 425-455.

51. Jefferys D, Funder J. The effect of water temperature on immobility in the forced swimming test in rats. European Journal of Pharmacology. 1994;253, 91-94. 
52. West AP. Neurobehavioral studies of forced swimming: The role of learning and memory in the forced swim test. Progress in Neuro-Psychopharmacology and Biological Psychiatry. 1990;14, 863-877.

53. De Pablo JM, Parra A, Segovia S, Guillamon A. Learned immobility explains the behavior of rats in the forced swimming test. Physiology and Behavior. 1989;46, 229-237.

54. Dal-Zotto S, Martí O, Armario A. Influence of single or repeated experience of rats with forced swimming on behavioural and physiological responses to the stressor. Behavioural Brain Research. 2000;114, 175-181.

55. Rittenhouse PA, López-Rubalcava C, Stanwood GD, Lucki I. Amplified behavioral and endocrine responses to forced swim stress in the Wistar-Kyoto rat. Psychoneuroendocrinology. 2002;27, 303-318.

56. Overstreet DH, Keeney A, Hogg S. Antidepressant effects of citalopram and CRF receptor antagonist CP154,526 in a rat model of depression. European Journal of Pharmacology. 2004;492, 195-201.

57. Chaki S, et al. MGS0039: A potent and selective group II metabotropic glutamate receptor antagonist with antidepressant-like activity. Neuropharmacology. 2004;46, 457-467.

58. Mague SD, et al. Antidepressant-like effects of $\kappa$-opioid receptor antagonists in the forced swim test in rats. Journal of Pharmacology and Experimental Therapeutics. 2003;305, 323-330.

59. Molina-Hernández M, Téllez-Alcántara NP. Antidepressant-like actions of pregnancy, and progesterone in Wistar rats forced to swim. Psychoneuroendocrinology. 2001;26, 479-491.

60. Estrada-Camarena E, Fernández-Guasti A, López-Rubalcava C. Antidepressant-like effect of different estrogenic compounds in the forced swimming test. Neuropsychopharmacology: official publication of the American College of Neuropsychopharmacology. 2003;28, 830-838.

61. Gersner R, Gordon-Kiwkowitz M, Zangen A. Automated behavioral analysis of limbs' activity in the forced swim test. Journal of neuroscience. 2009;180, 82-86.

62. Einat H. Partial effects of the protein kinase $\mathrm{C}$ inhibitor chelerythrine in a battery of tests for manic-like behavior in black Swiss mice. Pharmacological reports: PR. 2014;66, 722-725.

63. Foyet Harquin Simplice, Hritcu Lucian, Ciobica Alin, Stefan Marius, Kamtchouing Pierre, Cojocaru Dumitru, Methanolic extract of Hibiscus asper leaves improves spatial memory deficits in the 6- hydroxydopamine-lesion rodent model of Parkinson's disease, J of Ethnopharmacology, 2011;133(2):773-9.

64. Thakur AK, Tyagi S, Shekhar N. Comorbid brain disorders associated with diabetes: therapeutic potentials of prebiotics, probiotics and herbal drugs. transl med commun 2019;4, 12.

65. Lundstrom K, Pham HT, Dinh LD. Interaction of Plant Extracts with Central Nervous System Receptors. Medicines (Basel). 2017;4(1):12.

66. Katz MM, Koslow SH, Maas JW, Frazer A, Bowden CL, Casper R. The timing, specificity and clinical prediction of tricyclic drug effects in depression. Psychol Med 1987;17, 297-309.

67. Harmer CJ, Bhagwagar Z, Perrett DI, Vollm BA, Cowen PJ, Goodwin GM. Accute SSRI administration affects the processing of social cues in healthy volunteers. Neuropsychopharmacology 2003;28:148-152.

68. Mayorga AJ, Lucki I. Limitations on the use of the C57BL/6 mouse in the tail suspension test. Psychopharmacology (Berl) 2001;155, 110- 112.

69. Yoshikawa T, Watanabe A, Ishitsuka Y, Nakaya A, Nakatani N. Identification of multiple genetic loci linked to the propensity for 'behavioral despair' in mice. Genome Res 2002;12, 357-366.

70. Varty GB, Cohen-Williams ME, Hunter JC. The antidepressant- like effects of neurokinin NK1 receptor antagonists in a gerbil tail suspension test. Behav Pharmacol 2003;14, 87-95.

71. Chermat R, Thierry B, Mico JA, Steru L, Simon P. Adaptation of the tail suspension test to the rat. J Pharmacol 1986;17, 348-350.

72. Thierry B, Steru L, Chermat R, Simon P. Searching-waiting strategy: a candidate for an evolutionary model of depression?. Behav Neural Biol1984;41, 180-189.

73. Steru L, Chermat R, Thierry B, Simon P. The tail suspension test: a new method for screening antidepressants in mice. Psychopharmacology (Berl) 1985;85, 367-370.

74. Steru L, Chermat R, Thierry B, Mico JA, Lenegre A, Steru M, et al. The automated tail suspension test: a computerized device which differentiates psychotropic drugs. Prog Neuropsychopharmacol Biol Psychiatry 1987;11, 659-671.

75. Porsolt RD, Chermat R, Lenegre A, Avril I, Janvier S, Steru L. Use of the automated tail suspension test for the primary screening of psychotropic agents. Arch Int Pharmacodyn Ther 1987a;288, 11-30.

76. Porsolt RD. Animal models of depression: utility for transgenic research. Rev Neurosci 2000;11, 53-58.

77. Bai F, Li X, Clay M, Lindstrom T, Skolnick P. Intra- and interstrain differences in models of 'behavioral despair'. Pharmacol Biochem Behav 2001;70, 187-192. 
78. Renard CE, Dailly E, David DJ, Hascoet M, Bourin M. Monoamine metabolism changes following the mouse forced swimming test but not the tail suspension test. Fundam Clin Pharmacol 2003;17, 449-455.

79. Liu X, Gershenfeld HK. An exploratory factor analysis of the tail suspension test in 12 inbred strains of mice and an F2 intercross. Brain Res Bull 2003;60, 223-231.

80. Lucki I, Dalvi A, Mayorga AJ. Sensitivity to the effects of pharmacologically selective antidepressants in different strains of mice. Psychopharmacology (Berl) 2001;155, 315-322.

81. Porsolt R, Lenegre. A Behavioral models of depression. In: Elliott, J., Heal, D., Marsden, C. (Eds.), Experimental Approaches to Anxiety and Depression. Wiley, London.1992; 73-85.

82. Cryan JF, Page ME, Lucki I. Noradrenergic lesions differentially alter the antidepressant-like effects of reboxetine in a modified forced swim test. Eur J Pharmacol 2002b;436, 197-205.

83. Mombereau C, Kaupmann K, Froestl W, Sansig G, van der Putten H, Cryan JF. Genetic and pharmacological evidence of a role for GABAB receptors in the modulation of anxiety and antidepressant-like behavior. Neuropsychopharmacology 2004;29, 1050-1062.

84. Porsolt RD, Le Pichon M, Jalfre M. Depression: a new animal model sensitive to antidepressant treatments. Nature 1977; 266, 730-732.

85. Harkin AJ, Bruce KH, Craft B, Paul IA. Nitric oxide synthase inhibitors have antidepressant-like properties in mice. 1. Acute treatments are active in the forced swim test. Eur J Pharmacol 1999;372, 207-213.

86. Li X, Tizzano JP, Griffey K, Clay M, Lindstrom T, Skolnick P. Antidepressant-like actions of an AMPA receptor potentiator (LY392098). Neuropharmacology, 2001;40, 1028-1033.

87. Holt RI, de Groot M, Golden SH. Diabetes and depression. Curr Diab Rep. 2014;14(6):491.

88. Ghanei Gheshlagh R, Parizad N, Sayehmiri K. The Relationship Between Depression and Metabolic Syndrome: Systematic Review and Meta-Analysis Study. Iran Red Crescent Med J. 2016;18(6):e26523.

89. Luppino FS, de Wit LM, Bouvy PF, et al. Overweight, Obesity, and Depression: A Systematic Review and Meta-analysis of Longitudinal Studies. Arch Gen Psychiatry. 2010;67(3):220-229.

90. Gavril R, Hritcu L, Padurariu M, Ciobica A, Horhogea C, Stefanescu G, Spataru MC, Straulea C, Stefanescu C. Preliminary study on the correlations between oxytocin levels and irritable bowel syndrome in patients with depression. Rev.Chim.(Bucharest), 2019;70(6): 2204- 2206.

91. Cojocariu R, Ciobica A, Balmus IM, Guenne S. et al. Antioxidant Capacity and Behavioral Relevance of a Polyphenolic Extract of Chrysanthellum americanum in a Rat Model of Irritable Bowel Syndrome, Oxidative Medicine and Cellular Longevity, 2019, Article ID 3492767.

92. Balmus IM, Robea M, Ciobica A, Timofte D. Perceived stress and gastrointestinal habits in college students, Acta Endocrinologica, 2019 15: 274-275.

93. Ilie O, Ciobîcă A, Timofte D. A Mini-Review on the Correlation Between the Autistic Pathology and the Microbiome, Academy of Romanian Scientists Annals - Series on Biological Sciences. 2019;8(1):65 - 83.

94. Ilie O, Ciobica A, Timofte DV. The importance of the microbiome in the alzheimer disease pathology - the possible relevance of some metabolic deficiencies. Med. Surg. J. - Rev. Med. Chir. Soc. Med. Nat., Iaşi 2019;123(2):300-309.

95. Ilie O, Dobrin I, Ciobîcă A, Chiriță V, Timofte D. Current aspects on the relations that might exist between the schizophrenic pathology and gut microbiota - further metabolic relevance, Bulletin of Integrative Psychiatry. 2019;3(82):27-38.

\section{Correspondence}

Daniel Timofte,

MD, PhD, professor, "Grigore T.Popa” University of Medicine and Pharmacy, 16, Universitatii Street, 700115, Iasi, Romania, dantimofte@ yahoo.com

Submission: 20 oct 2019 Acceptance: 28 mar 2020 